\title{
BERBAGI KASIH DAN BERKAT ALLAH DENGAN KAUM MUDA
}

\author{
Ola Rongan Wilhelmus \\ STKIP Widya Yuwana \\ olarongan@widyayuwana.ac.id
}

\begin{abstract}
All the talents, potentials and abilities possessed by young people are a gift and blessing of God. Therefore, the Church is always present for young and is called to provide special assistance to them. The Church's efforts to provide assistance to the young people with such intention of helping them to find out the meaning of life; to realize their talents, potential, abilities, dreams and life expectancy is a success of the Church in building the future of the Church, society and the world. This is because the jurney and future of the Church, society and the world are truly in young people.
\end{abstract}

Keywords: youth, talents and abilities, accompaniment, future of the Church and the world.

\section{Pendahuluan}

Para pemimpin Gereja secara umum memandang kaum muda sebagai harapan dan masa depan Gereja. Pandangan ini berakar pada kecemasan dan kekhawatiran terhadap masa depan Gereja itu sendiri. Kekhawatiran itu terlihat dari sejumlah pertanyaan yang sering dilontarkan para pemimpin Gereja tentang: siapakah yang akan melayani Gereja pada hari esok? Siapakah yang akan menjadi guru agama Katolik dan Sekolah Minggu di kemudian hari? Siapakah yang akan menjadi misionaris dan pewarta Injil kelak? Jawaban untuk setiap pertanyaan ini ialah kaum muda. Para pemimpin Gereja senantiasa memandang kaum muda sebagai masa depan Gereja serta kekuatan penentu sejarah hidup dunia dan manusia.

Saat ini, banyak generasi tua sedih, gelisah dan putus asa karena perilaku hidup kaum muda yang semakin gencar mengidolakan budaya sibuk. Budaya ini identik dengan budaya sukses dan berbagai kegiatan yang dirasa penting dalam hidup. Budaya sibuk membuat banyak orang muda zaman now merasa tidak memiliki cukup waktu berdoa, menghadiri Ekaristi dan ibadat, membaca dan belajar Kitab Suci, melakukan devosi dan ziarah, serta terlibat dalam Gereja. Hadirnya sarana komunikasi elektronik seperti internet, iPhone, Twitter, Blackberry dan Whatsapp membuat banyak orang muda semakin sibuk dengan 
diri dan dunia sendiri. Hati dan pikirannya terus diisi berbagai macam kesibukan, tanggung jawab dan komitmen.

Berbeda dengan pandangan generasi tua, Gereja tetap memandang kaum muda sebagai aset dan kekuatan penentu sejarah hidup manusia dan peradapan dunia. Mereka adalah barometer kehidupan dan pelayanan Gereja saat ini dan hari esok. Allah terus mengundang dan memanggil orang muda menjadi misionaris dan pewartaan Injil. Allah membutuhkan kehadiran mereka untuk menjadi saksi hidup tentang Firman Tuhan yang membebaskan dan menyelamatkan setiap orang dari belenggu dosa dan penderitaan hidup.

Tulisan ini dibuat dengan tujuan: 1) mengidentifikasi sejumlah permasalahan kaum muda saat ini; 2) mendiskusikan pandangan Gereja tentang kaum muda; 3) mendalami tugas dan tanggung jawab Gereja dalam pendampingan kaum muda. Menjawabi tujuan ini maka tulisan ini mendiskusikan beberapa hal pokok yaitu: 1) kaum muda dan permasalahan hidup; 2) cinta Allah terhadap kaum muda; 3) kaum muda sebagai berkat bagi Gereja dan masyarakat; 4) kepedulian Gereja terhadap kaum muda; dan 5) Paus Yohanes Paulus II sebagai model pembina kaum muda.

\section{Kaum Muda dan Persoalan Hidup}

Generasi tua sering merasa terganggu dan kecewa terhadap perilaku kaum muda yang begitu tenggelam dalam kesibukan sendiri. Tidak jarang generasi tua dan para pendamping kaum muda merasa sakit hati dan marah saat melihat orang muda kurang peduli terhadap jerih payah dan kerja keras mereka dalam pendampingan kaum muda. Para pembina merasa tertekan dan bahkan putus asa saat melihat kaum muda semakin mengidolakan "budaya sibuk" yang sudah menjadi ciri hidup generasi millenial saat ini (Sara Clarke, 2014: 2).

Budaya sibuk membuat banyak orang muda merasa tidak memiliki lagi waktu untuk berdoa, menghadiri ibadat, membaca Kitab Suci, berziarah ke Gua Maria, dan terlibat dalam karya kerasulan Gereja. Bagaimana mungkin mereka bisa berdoa, membaca Kitab Suci, merenung serta refleksi tentang kehidupan iman dan hubungan pribadi dengan Tuhan jikalau hati dan pikiran mereka terus terisi dengan sekian banyak kesibukan, tanggung jawab dan komitmen (Sara Clarke, 2014: 5; Catholicsensibiliti. 2012: 4).

Kesibukan orang muda ini memicu sejumlah pertanyaan dalam hati generasi tua: Apakah kaum muda harus dipaksa pergi ke Gereja untuk mengikuti kegiatan Gereja?; Apakah mereka perlu didesak untuk mengorbankan relasi dan kedekatan hubungan dengan teman dan komunitas yang mereka sendiri bangun demi kegiatan kegiatan Gereja?; Apakah mereka perlu dibiarkan meninggalkan Gereja dan memilih sendiri agama dan praktek hidup rohani yang mereka kehendaki sendiri?. Cara generasi tua dan para pendamping merespon pertanyaan- 
pertanyaan terkait situasi hidup orang muda ini sangat menentukan masa depan hidup orang muda itu sendiri, Gereja dan masyarakat (Catholicsensibiliti. 2012:9).

Selain budaya sibuk, keterbatasan lapangan kerja, pengangguran, beratnya tekanan masyarakat konsumeristis saat ini juga mengakibatkan tidak sedikit kaum muda merasa tertekan, bingung dan tidak pasti. Ketidakpastian bertambah besar saat mereka mengamati dan mengalami bahwa sistem sosial, politik, ekonomi dan budaya yang dibangun di tengah masyarakat tidak sejalan dengan harapan dan pola pikir mereka. Situasi ini membuat mereka menjadi apatis, menjauh dari Gereja, dan bahkan malu mengikuti kegiatan Gereja (CNBB, 2012: 6). Berbagai pengalaman dan persoalan hidup orang muda ini sebetulnya merefleksikan kurangnya dukungan moral dan spiritual keluarga, sekolah, Gereja dan masyarakat serta lemahnya pendidikan dan pendampingan iman, kepribadian dan karakter kaum muda.

Orang muda saat ini mungkin sedang mengalami kekecewaan, kepahitan, kegetiran hidup, serta mengalami kekeringan rohani dan putus harapan. Hati dan pikiran mereka barangkali sedang terganggu oleh kegelisahaan hidup, tipu muslihat, penderitaan, kesedihan, ketakutan serta cobaan-cobaan hidup sejalan dengan pertumbuhan dan perubahan pribadi dalam diri mereka, serta realitas sosial, politik, ekonomi yang dihadapi. Situasi yang dialami ini bisa saja mengaburkan dan bahkan menghilangkan jalan yang membimbing mereka kepada perjumpaan dan persekutuan pribadi dengan Allah dan Yesus putera-Nya.

\section{Allah Mencintai Kaum Muda}

Kendatipun sibuk, mengalami ketidakpastian, kebingungan dan kekecewaan, kaum muda tetap memiliki kerinduan hati yang kuat untuk mengalami makna dan arti hidup, solidaritas, komitmen sosial, dan pengalaman religius. Hati kaum muda tetap terbuka lebar untuk diisi dengan persabatan, solidaritas, kualitas hidup, penghargaan serta perlindungan terhadap kodrat manusia. Kaum muda tetap memiliki kepekaan terhadap nilai-nilai keadilan, damai dan kelemahlembutan (GE, 1965, Art.2; Christifides Laici, 1988. Art. 46). Ditengah kegalauan hidup ini, Allah tetap setia mencintai, mendengarkan dan menerima kaum muda apa adanya. Gereja yakin bahwa Allah mencintai orang muda dan mengutusnya untuk menjadi pewarta Injil. Allah memberkati, menyertai perjalanan hidup, memberikan cahaya dan harapan kepada kaum muda kapan dan dimana saja (Catholicsensibiliti, 2012: 4).

Cinta Allah kepada kaum muda terungkap jelas dalam firman Tuhan: “tetapi Yesus memandang dia dan menaruh kasih kepadanya” (Mrk 10: 21). Yesus begitu mencintai kaum muda, cinta ini memberi jawaban secara utuh dan tuntas kepada setiap kerinduan hati dan harapan orang muda. Cinta Yesus mengandung kekuatan dasyat yang memungkinkan terjadinya perubahan total 
dalam diri setiap kaum muda. Hal ini terlihat dari sabda Yesus kepada seorang pemuda kaya: “...kemudian datanglah ke mari dan ikutilah aku” (Mrk 10:21). Sabda ini mengandung cinta dan panggilan Yesus atas diri kaum muda, dan sekaligus membuka kemungkinan terjadinya dialog kasih antara Yesus dan kaum muda. Sabda Yesus mengandung undangan kepada orang muda untuk terlibat dalam pewartaan Injil dan misi keselamatan Allah.

Undangan dan dialog kasih antara Yesus dengan kaum muda atas inisiatif Yesus ini merupakan landasan untuk dialog antara Gereja dan kaum muda. Dialog Gereja dan kaum muda yang dijiwai kasih memungkinkan terjadinya pertemuan, sharing iman, kasih dan suka cita. Melalui dialog ini, Gereja tetap memandang orang muda dengan penuh kepercayaan, harapan dan kasih sebab yakin bahwa kaum muda merupakan Gereja Yesus yang hadir secara nyata di tengah masyarakat, bangsa dan negara saat ini (bdk. Christifides Laici,1988. Art. 46).

\section{Kaum Muda Merupakan Berkat Allah Bagi Gereja dan Dunia}

Allah setia mencintai kaum muda dan Yesus terus melakukan dialog dan komunikasi cinta dengan mereka. Hal ini terjadi karena kaum muda merupakan kekuatan yang menentukan sejarah hidup manusia dan dunia. Kaum muda adalah Gereja Yesus Kristus yang hidup dan hadir di tengah masyarakat dan dunia. Jikalau kaum muda tidak memberi waktu dan perhatian kepada Gereja maka bisa dibayangkan Gereja akan kelihatan seperti apa untuk 10 atau 20 tahun ke depan.

Kaum muda sebagai Gereja Yesus Kristus yang hidup, hadir dan memberi kesaksian tentang cinta di tengah masyarakat dan dunia merupakan anugerah dan berkat Allah bagi Gereja, masyarakat dan dunia. Dikatakan demikian sebab kaum muda memiliki mimpi-mimpi dan harapan-harapan hidup yang bersumber pada Allah. Dalam lubuk hati yang terdalam, kaum muda memiliki kerinduan untuk mengerti dan mengalami makna hidup, solidaritas, komitmen sosial, dan pengalaman hidup rohani yang sebenarnya. Kaum muda terus membutuhkan pengakuan dan dorongan Gereja agar segenap potensi, kemampuan, mimpi dan harapan yang dimiliki bisa terwujud dalam hidup sehari-hari demi kebaikan serta kemajuan Gereja dan masyarakat.

Setiap potensi dan kemampuan dalam diri kaum muda merupakan anugerah dan berkat Allah. Karena itu Gereja selalu hadir bagi kaum muda serta terpanggil untuk memberikan pendampingan secara istimewa kepada kaum muda. Upaya Gereja membantu kaum muda menemukan makna hidup, serta mewujudkan potensi, kemampuan, mimpi dan harapan hidup merupakan keberhasilan Gereja membangun masa depan kaum muda. Tentang hal ini, dokumen Christifides Laici 46 menegaskan bahwa Gereja memberikan perhatian khusus kepada kaum muda serta merefleksikan keberadaan dan panggilannya 
dalam diri orang muda, sebab perjalanan dan masa depan Gereja dan dunia sesungguhnya ada dalam diri kaum muda.

Allah sendiri terus memanggil, memilih dan mengutus kaum muda untuk menjadi misionaris dan pewarta Injil. Allah mengundang mereka mengambil bagian secara penuh dalam gerakan evangelisasi atau pewartaan Injil. Allah membutuhkan keberadaan, kehadiran dan aksi konkrit mereka dalam Gereja, di tengah masyarakat dan dunia saat ini untuk memberi kesaksiaan tentang Firman Allah yang menyelamatkan serta membebaskan manusia dan dunia dari belenggu dosa dan kejahatan (Sara Clarke, 2014: 5; Catholicsensibiliti, 2012: 6).

Paus Yohanes Paulus II dalam suratnya pada tanggal 31 Maret 1985, menegaskan kepada segenap orang muda di seluruh dunia bahwa sebagaimana Allah sendiri mencintai dan membutuhkan kaum muda, demikian pula Gereja mencintai dan membutuhkan kaum muda serta memandang mereka secara unik. Sikap dan pandangan Gereja ini sudah terbentuk sejak zaman para rasul. Surat rasul St. Yohanes kepada kaum muda merupakan sebuah kesaksiaan penting bahwa sejak awal Allah sendiri menganugerahi Roh dan kekuatan bagi orang muda untuk mengalahkan kuasa jahat dan kegelapan. Sabda Tuhan: "Aku menulis kepada kamu hai orang-orang muda sebab kamu telah mengalahkan yang jahat”(1 John 2: 13).

\section{Gereja Peduli Terhadap Kaum Muda}

Keterbukaan kaum muda terhadap nilai, kualitas, potensi, mimpi, harapan hidup dari Allah telah menginspirasi dan mendorong para pemimpin Gereja dan pendamping kaum muda untuk memberikan perhatian khusus. Keberadaan dan keterbukaan kaum muda terhadap kualitas dan nilai-nilai hidup hendaknya semakin memicu kesadaran pemimpin Gereja dan pendamping bahwa pemahaman dan penghayatan orang muda terhadap nilai-nilai Injil dalam hidup sehari-hari merupakan suatu yang mendesak. Karena itu, orang muda perlu mendapatkan bimbingan dan pelatihan secara mendalam dan terprogram tentang nilai-nilai injil, iman, harapan, kasih dan doa. Kaum muda diberi motivasi supaya semakin terlibat aktif menjalani hidup sebagai rasul Tuhan di tengah masyarakat, terutama dalam komunitas kaum muda itu sendiri. Haparan menjadi rasul Tuhan ini sejalan dengan kerinduan Gereja akan kaum muda untuk memberi kontribusi yang semakin besar terhadap karya pewartaan dan kerasulan Gereja (EN, 1975. Art. 72).

Gereja sepenuhnya menyadari bahwa usia muda merupakan usia penuh semangat dan antusiasme untuk berbuat baik, melayani Allah dan sesama. Gereja tidak pernah merasa lelah memberi bimbingan dan dukungan serta mengajak orang muda untuk terus berkerja keras, membangun dan mengisi masa depannya secara baik dan bertanggungjawab (Sara Clarke, 2014: 5; Ghezzi Bert, 2016:4). 
Gereja juga tidak pernah merasa bosan berdialog, berdiskusi dan menulis tentang kaum muda. Hal ini bisa dilihat dari sekian banyak dokumen resmi Gereja tentang kehidupan orang muda sebagaiman tertuang dalam dokumen resmi Gereja, antara lain: General Catechetical Directory; Evangelii Nuntiandi; Catechesi Tradendae; Christifedeles Laici, dan lain-lain.

Gereja menyadari sepenuhnya bahwa kaum muda sedang mengalami masa-masa perkembangan dan pembentukan sosial, budaya, psikologis maupun religius. Dalam masa ini, tidak sedikit dari kaum muda mengalami kebingungan, merasa terasing, sakit hati, dikhianati, kehilangan arah hidup, dan tidak jarang diantara kaum muda ada yang meninggalkan imannya. Situasi ini mendorong Gereja untuk terus berupaya berdialog dan memikirkan dan merencanakan berbagai program pendampingan orang muda. Pendampingan dan dialog ini memungkinkan kaum muda bisa berceritera tentang persoalan dan pengalaman hidup sendiri, rasa sakit karena dikhianati teman, kehilangan arah hidup karena ditelantarkan orangtua atau orang-orang yang mereka cintai (Sara Clarke, 2014: 6). Tentang hal ini Uskup Brasil Don Jose Valmor Caesar sebagaimana dikutip oleh CNBB (2012: 7) mengatakan:

"Perjumpaan dan dialog dengan kaum muda merupakan suatu pertemuan istimewa. Karena hanya melalui dialog langsung dengan mereka, Gereja dapat mendalami berbagai hal terkait persoalan, kebutuhan dan kegiatan evangelisasi kaum muda.Momen-momen pertemuan dan dialog dengan kaum muda memungkinkan Gereja memiliki suatu pemahaman yang utuh tentang mereka”.

Kaum muda hendaknya dibimbing dalam suatu komunitas unik Gerejani yaitu komunitas kaum muda itu sendiri. Melalui komunitas ini mereka mendapat kesempatan bersosialisasi dengan sesama kaum muda lainnya. Disini kaum muda dilatih membiasakan diri membaca, memahami dan menghayati Firman Tuhan. Dalam komunitas ini kaum muda melatih diri berdoa, beribadah bersama dan melayani Gereja. Di tengah komunitas ini pula kaum muda boleh menggali dan mengalami bersama berbagai pengalaman sukacita, tantangan, rasa sakit, kekecewaan, putus harapan dan kesedihan. Kaum muda boleh berbagi bersama pengalaman memanggul salib dan bangkit lagi bersama Yesus (Sara Clarke, 2014: 7; Ghezzi Bert, 2016: 3).

Dalam komunitas Gerejani yang unik ini, kaum muda dituntun berjalan melewati lorong-lorong hidup secara pibadi dan bersama. Kaum muda belajar mengenal diri sendiri secara benar dan berdinamika bersama. Relasi dan kebersamaan yang dibangun bersama dalam komunitas Gerejani ini merupakan dasar dan tempat untuk belajar membangun rasa aman dan percaya diri. Dalam kebersamaan ini, tidak jarang kaum muda memunculkan berbagai pertanyaan 
kritis tentang cinta, dosa, pengampunan, penderitaan, kematian dan lain-lain (Bdk. AA, 1965. Art. 12; Dario CH, 1997: 21).

Dalam proses pembelajaran dan sharing ini, kaum muda tetap membutuhkan figur pendamping yang mampu berkomunikasi dan bekerjasama. Kaum muda masih tetap memerlukan figur pembina yang memiliki kesanggupan memediasi hidup dan kegiatan kaum muda dengan anggota komunitas seiman dan masyarakat. Sadar bahwa kaum muda tidak selalu memiliki dan menghayati nilainilai positif dalam hidup, maka para pembina merasa terpanggil dan bertanggungjawab mempromosikan hubungan baik antara kaum muda dengan komunitas Kristiani dan masyarakat luas. Hubungan ini perlu dibangun, sebab dengan demikian kaum muda dapat belajar, menerima dan menghayati nilai-nilai kemanusiaan di tengah masyarakat dan dunia (Dario CH, 1997: 27).

Saat melakukan pendampingan, para pendamping perlu memastikan bahwa bimbingan dan pelayanan tidak menciptakan tembok-tembok penyekat antara kaum muda, Gereja dan masyarakat. Para pendamping hendaknya rela meluangkan waktu mencari dan menemui kaum muda pada tempat-tempat dimana mereka biasanya berkumpul seperti halnya di mall, rental, warung kopi dan lainlain. Dalam pendampingan, hendaknya dihindari pandangan tentang kaum muda sebagai obyek pastoral Gereja sebab mereka adalah pribadi yang patut dihargai, dimotivasi dan didampingi supaya semakin mengerti dan terlibat dalam tugas perutusan Gereja dan pelayanan masyarakat. Kaum muda didorong memanfaatkan secara baik masa mudanya untuk menemukan jati diri sendiri dan membuat pilihan hidup yang tepat sesuai nilai-nilai Injil. Kaum muda butuh bimbingan ikhlas supaya bisa bertumbuh dan berkembang dalam rahmat dan kebijaksanaan di hadapan Allah dan manusia (Christifides Laici, 1988. Art 46).

Dalam perjalanan hidup, kaum muda umumnya mengalami masa puber dengan segala kelebihan dan kelemahannya. Dalam masa ini kaum muda biasanya mengalami gejolak dan dorongan cinta dan seksualitas yang kuat. Demikian pula pertumbuhan dan perubahan fisik, psikologis dan sosial dengan segala konsekuensinya. Dalam masa ini kerinduan untuk berada bersama orang lain menjadi begitu kuat. Berbagai pertanyaan mendasar terkait kekecewaan, frustasi dan lain-lain sering muncul. Menghadapi kenyataan ini, para pendamping perlu memiliki kepekaan tinggi terhadap aspek-aspek perkembangan dan perubahan yang terjadi dalam diri orang muda. Para pendamping perlu memiliki kemampuan dan keterampilan membantu dan mendorong mereka terlibat aktif dalam refleksi dan dialog tentang pemberian diri, kepercayaan diri, cinta kasih dan bagaimana menyalurkan cinta kasih itu secara benar. Para pendamping berupaya mengungkapkan diri Yesus sebagai sahabat, pembimbing, model hidup dan pribadi yang patut dicontoh dan disembah. Yesus merupakan ungkapan cinta kasih paling konkrit dari Allah kepada manusia melalui misteri penderitaan dan 
kematian Yesus. Hal ini akan memberi inspirasi kepada orang muda untuk memaknai penderitaannya sendiri, orang lain, masyarakat dan dunia di sekitarnya dalam terang kasih, kebaikan, penderitaan dan pengorbanan Yesus. Inilah dasar pembinaan dan pendampingan bagi orang muda (Catecheti Trandende, 1979. Art 38-42).

Masa muda merupakan masa dimana seseorang belajar membuat keputusan-keputusan penting dalam hidup. Akan tetapi dalam masa ini bisa saja banyak kaum muda masih menikmati dukungan keluarga dan teman. Meskipun demikian, kaum muda perlu belajar hidup dan menggantungkan diri pada kesadaran dan kemampuan sendiri. Karena itu para pendamping hendaknya secara perlahan-lahan dan menyakinkan untuk membantu kaum muda membangun rasa percaya diri, tanggung jawab pribadi dan tujuan hidup sendiri. Membantu kaum muda untuk memiliki keberanian dan kepercayaan diri menghadapi dan menyikapi secara benar realitas kebaikan dan kejahatan, rahmat dan dosa yang dihadapi. Pendampingan perlu memberi tekanan pada arti kebaikan bersama, keadilan, cinta kasih, perdamaian dan martabat manusia sebagai dasar pertimbangan saat mengambil keputusan. Pembina menghadirkan Yesus Kristus sebagai pribadi yang bisa memberi arti dan makna hidup, pribadi yang menginspirasi sikap dan semangat pengorbanan, keadilan, kedamaian dan takut akan Allah. Pola dan perilaku hidup yang dijiwai kasih Allah dan Yesus inilah yang membedakan kaum muda Katolik sebagai murid Kristus dari kaum muda lainnya (Catecheti Trandende, 1979. Art. 39).

\section{Paus Yohanes Paulus II Model Pembina Kaum Muda}

Paus Yohanes Paulus II memulai konsep yang sangat revelusioner tentang “Hari Kaum Muda Sedunia”. Siapakah diantara para Paus sebelumnya yang mampu menggerakkan ratusan ribu kaum muda di seluruh dunia? Keberadaan dan kehadiran Paus John Paulus II selalu memikat ratusan ribu kaum muda. Hal ini terjadi karena ia bisa berbicara secara sistematis dan terorganisir tentang kaum muda (Marybeth Bonacci, 2015:4).

Selama melakukan perjalanan kepausan sebanyak 104 kali, Paus Yohanes Paulus II tidak pernah absen bertemu dengan berbagai kelompok orang muda. Apakah Paus Yohanes Paulus II ingin bertemu mereka karena senang melihat wajah-wajah muda dan mendengarkan kata-kata pujian seperti: "Paus Yohanes Paulus II, kami mencintaimu”? Barangkali. Akan tetapi pertemuannya dengan kaum muda sudah pasti disebabkan oleh sesuatu yang lebih bernilai daripada sekedar ingin melihat wajah muda dan mendengar sorak-pujian. Paus Yohanes Paulus II gemar berjumpa orang muda sebab mereka adalah harapan dan masa depan Gereja (Marybeth Bonacci, 2015: 4-5). 
Paus Yohanes Paulus II sejak awal masa kepausannya mendukung agenda ekstrim kanan melawan aborsi, perkawinan di luar pernikahan, dan kotrasepsi. Agenda ini secara umum bertentangan dengan harapan kebanyakan kaum muda. Tetapi mengapa kaum muda begitu mencintainya dan berduyun-duyun datang kepadanya? Mengapa jutaan kaum muda rela berjalan melintasi benua dan samudera raya hanya untuk melihatnya? Mengapa kaum muda selalu mengatakan: “Paus Yohanes Paulus II, kami mencintaimu”? (Bonacci Marybeth, 2015:7; Bauman Michelle. 2016: 4-5).

Berbagai media tulis dan elektronik mencoba melukiskan alasan kaum muda begitu mencintai Paus Yohanes Paulus II. Padahal Paus Yohanes Paulus II terkenal mendukung agenda ekstrim kanan. Paus Yohanes Paulus II juga tidak memiliki apa-apa kecuali jubah putih dan mobil kepausan yang sering terlihat ia gunakan. Paus Yohanes Paulus II sebetulnya tidak memiliki sesuatu yang bisa didapatkan kaum muda. Meskipun demikian, mengapa kaum muda tetap berduyun-duyun datang kepadanya? Mengapa mereka tidak pernah bosan berseru: John Paul II, kami mencintaimu? Mengapa ketika Paus berbaring di atas ranjang kematian, ribuan orang muda datang dari berbagai benua memenuhi halaman kepausan untuk mendoakan Paus yang mereka cintai? (Bonacci Marybeth, 2015: 5-6).

Banyak awak media berupaya menjelaskan bagaimana kuatnya hubungan antara Paus Yohanes Paulus II dan orang muda. Kaum muda pada satu sisi kurang setuju dengan agenda ekstrim kanan dan kebijakannya, tetapi di sisi lain mengakui konsistensi Paus. Mereka menyukai fakta bahwa Paus memiliki kepribadian yang sangat bersahaja dan kebenaran dalam dirinya. Tidak bisa disangkal bahwa Karol Woytyla merupakan Paus yang dikaruniai dengan karisma luar biasa untuk kaum muda. Ia memiliki spirit kaum muda dan rasa humor tinggi. Mata hati cinta dan kekudusan hidup menarik dan memikat jutaan hati orang muda. Allah menggunakannya sebagai alat untuk berjumpa dengan kaum muda yang begitu dekat di hati Allah sendiri. Inilah yang membuat kaum muda begitu mencintai Paus Yohanes Paulus II (Bonacci Marybeth, 2015: 8).

Para seminaris dan imam muda yang sering menghadiri berbagai kegiatan kepausan Yohanes Paulus II memberi kesaksian bahwa Allah memberkati orang muda melalui Gereja dengan menggunakan Yohanes Paulus II. Dikatakan demikian sebab terdapat sekian banyak orang muda dari berbagai benua untuk mendengarkan apa yang dikatakan Paus. Kaum muda rindu berjumpa dengan Paus Yohanes Paulus II karena haus akan misteri pelayanan Paus yaitu "warta tentang kebenaran iman”. Kaum muda melihat didalam diri Paus terdapat cinta yang begitu dalam. Kaum muda mengalami Paus sebagai wakil kehadiran nyata Allah dan Yesus Putranya di tengah dunia (Michelle Bauman, 2016: 3; Bonacci Merybeth, 2015:8). 
Yohanes Pulus II dapat menunjukkan secara konkrit kasih Allah yang begitu agung, aktif, dan menantang itu melalui kepeduliannya kepada orang muda. Yohanes Pulus II percaya bahwa orang muda diberi bakat dan potensi yang begitu besar oleh Allah untuk kemajuan Gereja, masyarakat dan dunia. Karena itu Yohanes Pulus II mengarahkan orang muda supaya menggunakan potensi dan kemampuan itu secara bijak dan bertanggungjawab untuk kebaikan dan kebaruan manusia, masyarakat dan dunia (Michelle Bauman, 2016: 4; Bonacci Merybeth, 2015:7).

Ketika awak media bertanya kepada kerumunan orang muda dan pembina dari berbagai latar belakang usia, sosial, budaya dan bangsa tentang alasan mengapa menghadiri pertemuan bersama Paus, secara spontan kaum muda menjawab karena terinspirasi oleh ajakan dan ajaran Paus. Banyak pembina mengakui bahwa pelayanan Paus untuk kaum muda dari awal hingga saat ini merupakan produk ajakan dan pengajaran Yohanes Paulus II. Karena itu kaum muda datang untuk mendengarkan lagi Paus dan belajar tentang karya-karya Paus antara lain tentang teologi tubuh dan kesucian. Kaum muda datang mendengar tentang kebenaran-kebenaran iman yang diajarkan Paus dengan cara yang begitu sederhana, indah dan menarik. Kaum muda datang untuk belajar tentang bagaimana menemukan dan menghidupi cinta itu sendiri. Kaum muda ingin berbagi kepada manusia, masyarakat dan dunia pengalaman akan cinta yang mereka belajar dan dengar dari Yohanes Paulus II (Bonacci Marybeth, 2015: 8).

Paus Yohanes Paulus II merupakan manusia yang tidak hanya berprestasi besar tetapi juga meninggalkan sebuah tanda abadi untuk dunia. Orang kudus ini dikenang selamanya karena memiliki karakter luar biasa yang telah diperlihatkan semasa hidupnya. Salah satu karakter paling menonjol ialah mengabdikan diri secara total bagi orang muda. Paus Yohanes Paulus II mencintai kaum muda dengan cinta tulus dan manusiawi. Paus Yohanes Paulus II senantiasa merasa berkepentingan dalam hidup dan budaya kaum muda, serta memahami tantangantantangan yang dihadapi kaum muda dan memperlihatkan suatu affeksi istimewa bagi kaum muda itu sendiri.

Alasan yang paling mendasar bagi Paus Yohanes Paulus II begitu mencintai kaum muda ialah karena Paus memiliki kepentingan dengan kaum muda dan memiliki dedikasi serta ikatan batin yang begitu kuat dengan kaum muda. Paus Yohanes Paulus II sepenuhnya sadar akan betapa besar peranan kaum muda sebagai Gereja pada masa sekarang dan masa depan. Paus Yohanes Paulus II melihat kehidupan Gereja saat ini dan masa depan berada dalam diri kaum muda, dengan alasan ini maka Paus Yohanes Paulus II terus bekerja keras menyatukan dan membaharui hidup dan jiwa kaum muda. Paus Yohanes Paulus II terbuka mendengarkan kegembiaraan dan tangisan kaum muda. Paus Yohanes Paulus II memahami hati dan kerinduan kaum muda akan bimbingan. Paus 
Yohanes Paulus II merespon semuanya ini dengan memperhatikan energi, semangat dan cinta Ilahi atas diri kaum muda.

\section{Penutup}

Banyak generasi tua merasa terganggu dan kecewa melihat hidup kaum muda semakin tenggelam dalam kesibukan sendiri. Walaupun demikian, Gereja terus memandang kaum muda sebagai anugerah dan berkat Allah bagi Gereja, masyarakat dan dunia. Gereja terus menyadari bahwa kaum muda memiliki banyak bakat, potensi dan mimpi-mimpi hidup yang berasal dari Allah. Sadar akan potensi kaum muda ini maka Gereja terus merasa terpanggil membimbing dan menemani kaum muda agar semakin mampu, matang dan kuat menjalankan hidup secara baik sesuai rencana Ilahi. Gereja terus memberi bimbingan dan bantuan kepada kaum muda agar serius mempersiapkan dan membangun masa depan dengan baik.

Di tengah berbagai persoalan, kecemasan, ketakutan dan kebingungan hidup, setiap kaum muda tetap memiliki kerinduan hati untuk mengenal dan berjumpa dengan Yesus. Karena itu pendampingan terhadap kaum muda perlu dilakukan secara benar dan konsiten, walaupun sulit dan melelahkan kerena berbagai hambatan dan benturan dari dalam diri kaum muda itu sendiri maupun dari luar. Pendampingan kaum muda hendaknya dilihat sebagai sebuah panggilan Ilahi yang asyik dan menyenangkan karena kaum muda adalah harta karunia Ilahi dimana Gereja harus mencari, mendapatkan dan merawatnya. 


\section{DAFTAR PUSTAKA}

Bauman, Michelle., 2016, John Pope II: Pope of the Youth. http://www.catholicnewsagency.com/column/john-paul-ii-pope-of-theyouth-56/ Mai 16/2016

Bert, Ghezzi., 2010. Pope John Paul II and Young People. https://www.loyolapress.com/our-catholic-faith/scripture-andtradition/church-leadership/pope-john-paul-ii-and-young-people

Beth, Bonnaci Marry., 2012, The Pope of the Youth. http://www.catholiceducation.org/en/faith-and-character/faith-andcharacter/the-pope-of-the-youth.html

Catholicsensibiliti, 2012, GDC 182-183: The importance of youth for society and the Church. Posted on 15 March, ttps://catholicsensibility.wordpress.com/2012/03/15/gdc-182-183-theimportance-of-youth-for-society-and-the-church/h 2012

CNBB, 2012, Youlth is God's Gift to the Church and Society Today. Dalam: http://worldyouthday.com/youth-is-gods-gift-to-the-church-and-societytoday. Undo, 1 September 2017. , 1988, Dokumen Gereja Katolik, Christifides Laici (CL). , 1979, Dokumen Gereja Katolik, Catechesi Tradendae (CT). , 1994, Dokumen Gereja Katolik, Tertio Millenio Adveniente. 1975, Dokumen Gereja Katolik, Evangelii Nutiandi (EN). , 1965, Dokumen Gereja Katolik, Apostolicam Actuositatem (AA). 1965, Dokumen Gereja Katolik, Gravissimus Educationis (GE).

Hoyes, Dario Castrillon., 1997, An Overview of the General Catechetical Directory.

Sara, Clarke, 2014, What is the role of youth in the Church. https://youthministryconversations.com/what-is-the-role-of-youth-in-thechurch/, posted on January 2014 